Library Acquisitions: Practice and Theory, (1990), v.14, n.1, pp.101-111.

ISSN: 0364-6408

http://www.sciencedirect.com/science/journal/03646408

http://www.sciencedirect.com/science/journal/03646408/14/1

http://www.sciencedirect.com/science/article/pii/0364640890900505

http://dx.doi.org/10.1016/0364-6408(90)90050-5

(C)1990 Pergamon Press

\title{
REPORT OF THE ALCTS MIDWEST COLLECTION MANAGEMENT AND DEVELOPMENT INSTITUTE AUGUST 17-20, 1989
}

\section{CAROL PITTS HAWKS}

The Association of Library Collections and Technical Services (ALCTS) Midwest Collection Management and Development Institute, held in Chicago, August 17-20, 1989, continued the excellent reputation this particular institute has acquired. The Planning Committee Co-Chairs Gay Dannelly (Ohio State University) and Howard Dillon (University of Chicago) as well as committee members Anne S. Hudson (DePaul University), Joseph Branin (University of Minnesota), Nicholas Burckel (Washington University in St. Louis), David Farrell (University of California, Berkeley), Bonnie MacEwan (University of Missouri), Mark Sandler (University of Michigan), Eugene Wiemers (Michigan State University), and JoAnn King (ALCTS staff) developed a dynamic program. The General Sessions included provocative speakers such as Beverly Lynch (University of Illinois at Chicago) and Robert Hayes (University of California, Los Angeles) who focused their presentations on the larger issues of collection management and development.

The Issue Sessions were moderated primarily by the members of the planning committee and emphasized practical issues such as collection policies and budgeting methods. Each daily session ended with a discussion group meeting. These groups were constructed of participants with similar responsibilities and from similar-sized institutions. The purpose of these groups was to discuss issues raised during the day and to provide an environment conducive to networking.

\section{GENERAL SESSIONS}

\section{Keynote Address: The Library's Collection and the Library User-}

\section{Beverly Lynch, University of Illinois at Chicago}

The thesis of Lynch's presentation was "to place the importance of collections ... in the context of user needs." Two assumptions prefaced the rest of the presentation. First, much of the published information and research about libraries is based on the 112 ARL libraries giving them an extraordinary amount of influence on policy development. Second, her point of view was that of 
a director who is very interested in building on-site collections.

The importance of knowing one's own environment before beginning to plan cannot be overstated. The rapid growth of the University of Illinois at Chicago (UIC) from an undergraduate commuter school in 1977 to a research university whose library joined the ARL in 1989 makes it an excellent example of the ever-changing campus environment. The organization of UIC selection includes a small group of bibliographers reporting to a Principal Bibliographer. These bibliographers select all material for the UIC libraries. This highly centralized model separates collection development from geographic location. Branches do not have collection development budgets.

Four UIC collection development practices provoked a great deal of discussion from the participants. The first practice, simply put, is to collect to the level taught. In other words, the in-depth, comprehensive collections reflect the academic programs. The second practice is to allocate the materials budget to a few large funds such as Science. Eliminating detailed subject breakdowns eliminates the problem of reporting expenditures for each academic department. The third practice is that no more than $50 \%$ of the budget should be spent on serials (although the $50 \%$ figure is for the budget as a whole, it is not translated equally in each bibliographer's budget). The fourth practice is to acquire routinely the output of scholarly presses in the U.S. and Great Britain.

Lynch then moved to a discussion of "Who is the user?" In addition, are some users more important than others? How and who decides that? Lynch emphasized that librarians must understand how scholars do their work. Librarians cannot afford to ignore some of their most important users: graduate students and new assistant professors. These beginning scholars use the library heavily but are not considered powerful on most campuses.

In the area of collections, Lynch stressed the importance of on-site collections as the primary focus of research libraries. Collections must be viewed comprehensively, including both special collections and current materials. Positive steps must be taken in the area of preservation.

Lynch concluded with four points. Libraries must get control of serials budgets, or someone else will. On-site collections are essential. Users require constant attention. The environment must be systematically monitored, resulting in appropriate responses by the library.

\section{Managing Information: Implications and Strategies in the Electronic Age-}

\section{Robert Hayes, University of California at Los Angeles}

According to Hayes, the librarian has two professional imperatives: preservation of the record and providing access to the record. In addition, there are three corollary commitments which determine policies. These commitments include open availability of information, free service, and cooperation. These imperatives and corollaries are "the driving forces in determining professional priorities."

Strategic planning for information resources in the research university is imperative. Planning involves three phases: strategic or long-range planning (5- to 20-year goals), tactical planning (6 month to 2-year goals), and operational planning (day to day). However, these three levels of planning must interact closely. The disadvantage to this approach is that it ties planning to what is already known and may fail to recognize new trends which may depart radically from the known - a considerable risk in the area of information.

Hayes discussed a number of information management projects which were funded by 
UCLA. These individual projects can be categorized into several needs or trends which will be, or already are, affected by the provision of information resources. These trends include the importance of digitized images in campus instruction, electronic mail and telefacsimile transmission, database consultation and downloading, project management, development of integrated library and telecommunications computer systems, information centers focused on specific subjects, indexing and abstracting, instructional interfaces, expert system development, desktop publishing, and off-campus access services.

Several external issues will affect the library's ability to respond to a constantly changing environment. These external issues include changing methods of publication and distribution of information, relationships with the information industry, pricing policies, copyright, government policies related to open access to information, and the shift of sources of capital from government to private/industry sources.

In conclusion, Hayes identified the responsibilities of top library management to provide the vision, to develop the mission, goals, and objectives, and to identify and prioritize issues of strategic importance. Finally, the planning process must be action-oriented, incorporate timelines, and define who is responsible for each action.

\section{Application of Automation to Collection Management: Sources \& Systems-}

\section{Nancy Sanders, Ohio State University}

Sanders began her presentation with a litany of the trials of collection managers in acquiring needed data from existing automated systems. In fact, no automated system has been designed with collection management as a major component. What does exist is usually an afterthought or a by-product of other functions.

Pieces of the desired system are available from a variety of sources including the North American Collections Inventory Project (NCIP)/Conspectus On-line, the OCLC/AMIGOS Collection Analysis System, and the OCLC/AMIGOS Tape Analysis Project. The Conspectus On-line assists the library in determining the total level of support for a subject area within the collection. Comparison of the library's collection to those of other Conspectus participants is easily achieved. The PC version of the Conspectus developed by the University of North Carolina-Chapel Hill extends the power of the Conspectus to smaller libraries which do not qualify for inclusion in the Conspectus On-line.

The OCLC/AMIGOS Collection Analysis System is available in CD-ROM and tape versions. This "context analysis" counts each item only once and provides statistics on the uniqueness of the library's collection when compared to a selected group of peer libraries. The library has some choice in the selection of its peer group, and the system identifies overlaps and gaps in the collection when compared to those peers. In addition to statistics, the system provides brief bibliographic records. The issues of cataloging idiosyncrasies and record duplication are significant in a system which derives its information from the OCLC database. The recently published Books for College Libraries' third edition (BCL3) is also available in automated form* and is part of the OCLC/AMIGOS product. However, for a research library, this "recommended list" approach is adequate only for assessing a library's holdings of basic works.

Collection development and management information is also available through use of acquisition/serials control systems and products which currently exist. The Books in Print and 
Ulrich's series have been released in CD-ROM format. These products allow searching through a variety of keys, such as subject, and employ Boolean logic to develop lists such as all 1989 titles in the area of costume history.

Local integrated systems including online catalogs, circulation, and acquisitions can provide information for collection managers. For example, the INNOVACQ system at Ohio State (OSU) can provide many lists and statistical reports through its Boolean search capabilities. OSU's online catalog, LCS, can extract the number of titles in the cataloged collection by classification categories. However, special analysis requests require special programming and must be queued until programmer time is available.

It is now time to plan for the next generation of library systems development. It is essential that collection management form an integral component of these new systems. The fifteen state-assisted universities in Ohio have had the opportunity to develop an RFP for a statewide automated library system, the Ohio Library and Information System (OLIS). During this process, the requirements of the ideal collection management system have been identified.

The general characteristics of the system include user-friendliness, the regular production of routine reports, the ability to capture and store transitory data, and the accessibility of data on a real-time basis. The system functions must provide cost information; collection growth patterns; use patterns; strengths and weaknesses assessment data; rapid data availability; data for storage, weeding and preservation decisions; cost projection capabilities; and the data to document access to information, not just ownership.

The OLIS collection management specifications include three parts: the general functional specifications which apply to the entire system, data to be collected and retained, and desired reports. The document suggests creation of a separate file to hold the collection management information and a three-level report generating structure. Finally, the system must have the ability to track and maintain transaction data for at least 5-10 years, user data for the same period, and acquisitions/serials cost data.

\section{Panel Discussion: \\ Cooperation \& Resource Sharing-}

\section{David Farrell, Moderator, University of California, Berkeley}

Farrell issued three statements for the participants to consider during the panel discussion:

1. The nature of collections is changing.

2. Collection management is fundamentally a public service function.

3. Technology has produced a revolution in the knowledge industry.

In addition, he posed three questions for consideration: Does the user know what he wants? Where do libraries find the time to cooperate? How much does it cost?

\section{Cooperation and Resource Sharing: the Illinois Experience-}

\section{Doris Brown, DePaul University}

The state of Illinois has been involved in resource sharing since the early 1960s. Illinet 
Online (IO) is a statewide catalog and circulation system as well as the local catalog for over 800 Illinois libraries. The system includes 18.3 million volumes and over four million titles. In addition, IO may be enhanced to include dial access to CARL's Uncover periodical article file, and the loading of the Wilson Indexes is being explored.

Cooperative collection development is a much more recent development for the state of Illinois. A pilot staff exchange between three of the institutions is intended to provide collection development education to establish a common knowledge base. A collection development fund competition is now in place. IO can also be used to flag the last copy of a title in the state and to note its preservation status. The initial concern that statewide funding will be reduced due to cooperative collection development has been allayed somewhat.

\section{A National Perspective: the Center for Research Libraries-}

\section{Ray Boylan, Center for Research Libraries}

Boylan began by stating that research libraries cooperate out of necessity. If libraries cannot achieve something alone, they will cooperate. In addition, patron demand has increased just as the availability of information has increased. The Center for Research Libraries (CRL) collection is intended to complement and supplement the collections of its members. The average annual membership fee is $\$ 24,500$. The acquisitions policy is constantly monitored to ensure that members' collections are not duplicated.

Two benefits occur from membership in CRL. The system reduces the costs of providing access to certain classes of materials such as newspaper backfiles. The system also leads to the acquisition of unique material that simply would not be available anywhere else. However, these benefits are difficult to see in times of tight budgets, particularly since much of this material would be considered a low priority. Boylan stated three conditions which will ensure the success of cooperative programs. First, staff at the local level must understand what the cooperative program is meant to achieve. Second, the interlibrary loan staff must understand cooperative ventures. Finally, the patron should find the items acquired cooperatively in their local systems.

\section{Getting Into a Cooperative Posture-}

\section{Ann Thompson, University of Cincinnati}

Thompson began by identifying eight issues and current realities concerning cooperative collection development:

1. There is no formula for a successful program. There are models but each environment is unique.

2. The process is political, moving beyond professional ethics to campus and local politics.

3. Effective communication is essential.

4. Enlightened, persistent leadership from librarians is critical.

5. The mechanics of the process can take many forms.

6. Technology has an increasingly consistent and controlling role. 
7. Measurement techniques must be redefined.

8. Evaluation techniques must be better defined and more frequently revised.

There are three concerns or realities which must be addressed. First, libraries fear a loss of status and individuality as independent, distinct libraries. Librarians developed the standards for evaluating collections and, thus, can change them to reflect the access vs. ownership issue. Cooperation will increase access; it will not save money. Second, libraries have a tendency to react rather than to plan. Librarians must be prepared to plan, act, and, above all else, lead. Finally, libraries must consider where and when patrons need information. On-site versus off-site, access versus ownership issues must be considered.

Thompson concluded with several calls to action. Cooperation will take many forms; no one is exempt. Technology can be our tool or our nemesis. Librarians must take the leadership role.

\section{Libraries and Funding: The Politics of the Budgetary Process in an Era of Decreasing Resources-}

\section{John Howe, University of Minnesota}

By way of an introduction, Howe indicated that he had been an historian for 27 years and an interim library director for 2 years. Howe emphasized the importance to the library of external relations. One must build political support and raise the library on the academic priorities list. This is imperative as a preface to the budget process. The three subcultures of librarians, teaching faculty, and university administrators must be brought together. The level of a unit's budget has a psychological and emotional effect. For example, the size of the budget often equals the esteem in which the unit is held. The long-term underfunding of libraries must be corrected.

Howe addressed the "de-centering" of the library within the university. Six reasons for this "de-centering" were identified:

1. The rise of new information technologies competing within and outside the university, including a growing number of information vendors.

2. The decline of traditional arts and sciences curriculum. Traditional librarianship has languished as well.

3. The disruptive changes within the profession of librarianship such as new technologies.

4. Important changes in the way the universities conduct their administrative duties, such as competition for resources and pressure from outside for accountability.

5. Profound changes in the financing of both public and private universities including increased reliance on external sources of income.

6. The importance of the library to learning and the curriculum has not been reiterated often enough.

The well-being of the library depends on assertive, effective leadership. This "de-centering" has rendered the library unable to meet user needs.

Howe concluded with five remedies to tailor political strategies to the environment: 
1. The essential task of constituency building. Libraries have no natural constituency, so the library must be marketed to university administration.

2. Necessity of a clearly articulated, carefully developed strategic plan. The plan must be forward-looking and change-oriented. It must convey a vision of the future and speak persuasively to various constituencies.

3. Understanding of the planning process in which decision-making is made. This requires a knowledge of essential decision points in order to be well-positioned when they arrive.

4. The library as a major player in the formation of institution-wide information policies.

5. Putting the library's own internal business in order. The library must show that existing resources are being used wisely.

Howe ended with an analysis of his first day as interim library director. "[He] went home and slept like a baby. That is to say-[he] awoke every 2 hours crying."

\section{ISSUE SESSIONS}

\section{Collection Policies-}

\section{Louis Pitschman, University of Wisconsin}

Pitschman provided a very thorough discussion of what a policy statement is, why a statement is important, and how to develop a statement. No matter how long the library plans to spend on policy development, it will take much longer. In addition, Pitschman responded to questions such as What is the relationship between collection evaluation and a collection development policy, i.e., which should you do first, and how should the faculty be involved in policy development?

\section{Preservation-}

\section{Robert Mareck, Michigan State University}

Mareck began with a definition of preservation selection emphasizing the difference between selection for preservation and selection in preservation. Selection for preservation involves decisions as to what material should be preserved. Selection in preservation involves what options are available for preservation. Mareck identified eleven preservation options or techniques including commercial rebinding, replacement, in-house repair, protective enclosure or phase boxes, polyester encapsulation, deacidification, discard, no action/reshelve as is, remove to protective environment, microfilm, and restoration/conservation. Mareck then split the participants into working groups which evaluated actual material and recommended appropriate treatment.

\section{Publish or Perish-}

\section{Mark Sandler, University of Michigan}


Although this was a somewhat misleading title, this session focused on why collection managers should or do publish. Sandler divided the participants into working groups to identify why individuals publish. The individual groups then reported their discussion to the entire group. The majority of the reasons expressed focused on altruistic reasons such as the desire to share information and for the increased good of the profession. However, one particular group focused on more selfish reasons such as promotion and tenure requirements, desire to enhance one's professional reputation, and finally, the ego-enhancing benefits of publishing.

\section{Collection Assessment \& Evaluation-}

\section{Bonnie MacEwan, University of Missouri}

MacEwan began her presentation with discussion of the three models of selection in academic libraries: historical (faculty selection), shared authority (faculty input/librarian selection), and research (librarian-controlled selection). MacEwan then discussed specific assessment and evaluation projects including the National Shelflist Count, the North American Collections Inventory Project/Conspectus, the University of North Carolina-Chapel Hill Conspectus PC Program, the OCLC/AMIGOS Collection Analysis CD-ROM, course analysis and faculty research profile at Arizona State, Books for College Libraries and other tape based programs, and user based methods.

\section{Budgeting Methods-}

\section{Eugene Wiemers, Michigan State University}

Weimers' presentation focused on the various goals of budgeting - those of the library, the institution, and the collection development officer (CDO). Library goals include choices in subject and formal, between current and retrospective material, between collecting and preserving, and among local, remote and shared resources. Institutional goals and the political environment of the parent organization influence the level of funding allocated to the library. The goals of the CDO include the distribution of resources, the establishment of a fiscal framework, and the providing of autonomy and accountability. Finally, Weimers listed four things that a budget cannot do - control selection, change institutional values, overcome weak selectors, or substitute for accounting.

\section{Use and User Studies-}

\section{Kris Brancolini, Indiana University}

Brancolini began by identifying the differences between use and user studies. Use studies begin with the collection and try to determine what is being used. User studies begin with users and try to determine what they are using and why. The types of evaluation studies include collection-centered evaluations such as list checking, client-centered evaluations such as circulation studies, and citation analysis evaluations. Brancolini discussed the planning and implementation of a major user survey at Indiana. In addition, she outlined problems encountered in the process of gathering and evaluating the data. Brancolini concluded with several questions which need to be asked about user surveys such as What is the validity of the faculty's feelings 
about the collection? and Should research libraries put much emphasis on use?

\section{Friends Groups and Development Programs-}

\section{David Farrell, University of California, Berkeley}

Farrell began with a discussion of when a Friends program is useful. He identified the objectives of such a program and why the collection development officer should be involved. The typical organizational structure for large and mature programs as well as that of small and beginning programs was identified. Farrell continued with discussion of planning, staffing, and institutional issues in developing a new or enhancing an existing Friends group. Farrell concluded with discussion of several key issues: the organization of the library's internal operations, institutional relationships, donor acquisitions, and cultivation of major prospects.

\section{Censorship-}

\section{Joseph Branin, University of Minnesota}

Branin began with an historical overview of censorship and intellectual freedom. In addition, he posed the question of whether librarians/ALA should take a position on social issues such as the Vietnam War, the Equal Rights Amendment, and apartheid. The difference between selection and self-censorship was explored extensively with particular emphasis on Asheim's 1953 article on that topic. The best strategy to avoid self-censorship is to be sure that selection is a part of well-managed, comprehensive collection development program. The usual bases for censorship include sexual propriety, political views, religious views, minorities/racial prejudice, and government censorship.

\section{Panel Discussion - \\ What to Do When You Get Home: Organization, Training and Evaluation for Collection Management}

\section{Gay Dannelly, Moderator, Ohio State University}

Dannelly provided a brief summary of the main issues and emphases that had emerged over the past three days. Four themes had emerged: high sensitivity to the environment, strategic planning, technology, and communication. She indicated that the focus of this panel was on how to take the information from the institute and implement it at home. In addition, she announced that since many of the speakers had strongly encouraged risk-taking, the panel would conclude its presentation with a risk-taking venture.

\section{Romaine Ahlstrom, Los Angeles Public Library}

Ahlstrom spoke of her own experience at LAPL after attending the pilot Collection Management and Development Institute at Stanford. It took one year to persuade the Chief Librarian that a collection development policy was important; another year was required to persuade the subject specialists to participate. A Dewey classification breakdown was developed 
in 1983/84 since at that time the Conspectus employed LC classification only. Draft policies were completed in 1984/85 with the first devastating LAPL fire occurring in April 1986. In this fire, over 250,000 volumes in science were lost. The library began a reanalysis of the existing collection to develop a plan for rebuilding. Books were purchased and stored in boxes. The remaining collection was inventoried. Arco subsequently raised over $\$ 10$ million to rebuild the collections in its Save the Books Campaign. Finally, the collection policy was used as a tool for training new staff who had never worked at the central library.

\section{Marcia Pankake, University of Minnesota}

Pankake made three broad suggestions for the participants when they returned home. First, participate in collection development in as broad an environment as possible. Second, the greatest advances are made by working together; so, build on each other's work. Finally, the library is an independent source of strength, not servile to other needs. Three admonitions were also offered. Gradual, evolutionary change is the best and lasts longest; take the long view and persevere. Be systematic and open. In fact, if you have not made any mistakes, fabricate them; then, others will not expect you to be perfect.

Pankake concluded with a number of immediate actions. Work to have collection development activities incorporated into job descriptions, evaluations, and annual goals and objectives. Do not add additional responsibilities without changing your other priorities. Skill and speed will increase over time. Exercise control over your work. Finally, Pankake cited Kenneth Blanchard's The One-Minute Manager concerning about working smarter, not harder. His formula for success follows:

$\underline{\text { Specific goals }}$

Measurable

Attainable

Relevant

Trackable

\section{What Now? Mobilizing the Motionless, Inspiring the Expired, and Titillating the Tranquil}

\section{Dana C. Rooks, University of Houston}

Rooks identified her role as the last speaker to inspire the participants to implement what they had learned when they returned home. Change cannot be successfully implemented except in concert with others. The person initiating change must be able to convince others of the need for the change. Rule number one in implementing change is openness and honesty throughout the process. The second aspect of implementing change is how it will be done. Before suggesting an enhancement, one must analyze that enhancement thoroughly. The third aspect is to reach a consensus of support for what is to be achieved. A clear understanding and articulation of what is to be accomplished is essential. Finally, there must be a reward or benefit from the change.

\section{CLOSING}

As had been promised, the members of the final panel proceeded with their risk-taking 
venture- a musical performance of the following lyrics by Marcia Pankake, sung to the tune of Home on the Range:

Oh give me a home

Where librarians roam

And the students and faculty play

Where never is heard

A discouraging word

And the systems are up night and day.

Home, home with the books

With our MRDF's and CD-ROMs, too

With government docs, indexes, and bibs

We've enough information for you.

Oh let me go home

Amid collections to roam

To manage or buy all the day

With assessments to do

And policies, too

There's not enough time in the day.

Home, home with the books

With our MRDF's and CD-ROMS, too

I've got new colleagues here

I need have no fear

Turn me loose, I've got so much to do! 